\title{
Early effects on the intestinal barrier and pancreatic function after enteral stimulation with protease or kidney bean lectin in neonatal rats
}

\author{
Ester Arévalo Sureda $^{1 *}$, Olena Prykhodko ${ }^{1,2}$ and Björn Weström ${ }^{1}$ \\ ${ }^{1}$ Department of Biology, Lund University, Solvegatan 35C, SE 223 62, Lund, Sweden \\ ${ }^{2}$ Food for Health Science Centre, Lund University, Box 124, SE 221 OO, Lund, Sweden \\ (Submitted 29 August 2017 - Final revision received 30 November 2017 - Accepted 8 January 2018 - First published online 19 February 2018)
}

\section{Abstract}

Gut maturation naturally accelerates at weaning in altricial mammalian species, such as the rat. Mimicking this, gut development can also be induced precociously, 3-4 d earlier than it would occur naturally, by enteral exposure to phytohaemagglutinin (PHA), or various proteases. We investigated the early effects of gut provocation on intestinal barrier and pancreatic functions, to get a better understanding of the mechanisms that initiate gut maturation. The effects of oral administration of protease (trypsin) or PHA to 14-d-old suckling rats were studied during $24 \mathrm{~h}$ in comparison with water-fed controls. Intestinal in vivo permeability was assessed by oral administration of different-sized marker molecules and measuring their passage into the blood or urine $3 \mathrm{~h}$ later. A period of $24 \mathrm{~h}$ following oral administration, both PHA and protease provocation stimulated small intestinal (SI) growth and pancreatic secretion, as indicated by decreased pancreatic trypsin and increased luminal enzyme content. Within $1 \mathrm{~h}$ of oral administration, both treatments prevented the absorption of macromolecules to blood that was observed in controls. PHA treatment hindered the passage of fluorescein isothiocyanate-dextran (FD) 4 to blood, whereas protease treatment temporarily increased plasma levels of FD4, and the urine lactulose:mannitol ratio, indicating increased intestinal leakiness. Following protease treatment, fluorescence microscopy showed decreased vesicular uptake of FD70 in the proximal SI and increased epithelial fluorescence in the distal SI. In conclusion, PHA and protease differed in their early effects on the intestinal barrier; both exerted a blocking effect on epithelial endocytosis, whereas protease treatment alone temporarily increased epithelial leakiness, which seemed to be confined to the distal SI.

\section{Key words: Gut: Permeability: Precocious maturation: Small intestine}

Gastrointestinal development in the rat progresses during the 1st few postnatal weeks, following changes in the diet and the gut microflora within the protective milieu provided by the maternal $\mathrm{milk}^{(1)}$. Digestive function is well suited to the milk diet after birth; however, during the 3rd postnatal week, with the transition from milk to a solid food diet, that is, weaning, the maturation process markedly accelerates and is completed around postnatal day $25^{(2)}$. This results in growth of the gastrointestinal organs and prominent shifts in the small intestinal (SI) structure and function. In addition, the pancreas, an accessory organ of the gastrointestinal tract, is affected with increased production and secretion of digestive enzymes ${ }^{(3)}$.

During the suckling period in rodents, the immature intestine is highly permeable allowing passage to the general circulation of intact milk-borne bioactive compounds by the highly endocytic SI epithelium $^{(4)}$. The selective uptake of milk antibodies (IgG) involves binding of IgG to the neonatal Fc-receptors (FCRn) in the proximal SI, whereas the non-selective uptake of macromolecules involves the supranuclear vacuoles in the digestive enterocytes within the distal SI. During the maturation process at weaning, these immature fetal-type enterocytes are replaced by more differentiated adult-type enterocytes, which are FcRn-negative and non-vacuolated in the proximal and distal SI, respectively ${ }^{(5)}$. This shift in the epithelial features of the SI results in a markedly decreased permeability, that is, gut closure, with improved intestinal barrier function ${ }^{(4,6)}$.

Despite being genetically pre-programmed, gastrointestinal development can be induced $3-4 \mathrm{~d}$ before natural weaning (postnatal day 21) by removing the rat pups from their dam ${ }^{(7)}$ or by injecting the pups with corticosteroids ${ }^{(8)}$. In addition, enteral provocation with polyamines (spermine) ${ }^{(9)}$, the lectin from red kidney beans, phytohaemagglutinin (PHA) ${ }^{(10)}$ or pancreatic and pancreatic-like proteases ${ }^{(11)}$ has also been shown to induce precocious gut maturation. The progression of PHA-induced maturation has been previously studied and revealed an early phase occurring within $24 \mathrm{~h}$ following treatment, in which PHA bound to the gastrointestinal epithelia causing mucosal disturbance with villi atrophy, release of pro-inflammatory cytokines and recruitment of lymphocytes to the gut mucosa,

Abbreviations: BIgG, bovine IgG; b.wt, body weight; FD, fluorescein isothiocyanate-dextran; HSA, human serum albumin; Lac:Man, lactulose:mannitol ratio;

PAR-2, protease-activated receptor-2; PHA, phytohaemagglutinin; SI, small intestine.

* Corresponding author: E. Arévalo Sureda, email ester.arevalo_sureda@biol.lu.se 
as well as enhanced pancreatic secretion ${ }^{(12,13)}$, finally leading to gut maturation following $72 \mathrm{~h}$ after PHA administration.

The aim of this study was to investigate the early effects of enteral provocation with protease in comparison with that of PHA, with emphasis on intestinal barrier function and the exocrine pancreatic function. The integrity and maturity of the barrier function were estimated by measuring the intestinal permeability, passage and uptake of marker molecules of different molecular sizes and properties. Hence, the purpose of the study was to get a better understanding of the mechanisms responsible for initiating gut maturation and the early effects on the gut after luminal stimuli.

\section{Methods \\ Animals}

The experiment was approved by the local Malmö-Lund Ethical Review Committee for Animal Experimentation and conducted in accordance with the European Community regulation concerning the protection of experimental animals (2010/63/EU). The studies were carried out using rats (Rattus norvegicus) of the Sprague-Dawley strain (SPRD Han; Taconic M\&B). The rats were bred and kept under specific pathogen-free conditions in the departmental animal facility at Lund University $\left(20 \pm 1^{\circ} \mathrm{C}\right.$, $50 \pm 10 \mathrm{RH} \%, 12 \mathrm{~h}$ light $-12 \mathrm{~h}$ dark cycle). Before parturition, the pregnant dams were moved to individual cages (polycarbonate) with aspen wood bedding (Beekay B\&K Universal AB), enriched with paper-nesting material (Sizzle-pet; Lillicobiotech). Parturition date was denominated as day 0 , the litter size was culled to eleven to thirteen rat pups and all rat pups were kept with their dam during the experiments. The adult rats had free access to water and a rodent laboratory chow (R3, Lactamin) placed on the cages lid; however, the cage height was increased using a $7-\mathrm{cm}$ wall extender to prevent access to the solid chow by the pups.

\section{Experimental design}

The effects of gut provocation were studied in 14-d-old suckling rats at $1,4,8$ and $24 \mathrm{~h}$ after receiving one of two different treatments. The protease, porcine pancreatic trypsin (Novo), at a dose of $0.8 \mathrm{mg} / \mathrm{g}$ body weight (b.wt) or the lectin, PHA purified from red kidney beans ${ }^{(14)}$, at a dose of $0.1 \mathrm{mg} / \mathrm{g}$ b.wt were administered via a flexible stomach tube. Control pups received the vehicle, water, administered at a volume of $0.01 \mathrm{ml} / \mathrm{g}$ b.wt. The dosage of PHA and protease was established in previous studies and considered as effective doses by the capacity to induce precocious maturation of the SI epithelium $3 \mathrm{~d}$ after administration - that is after exchange of the intestinal epithelium ${ }^{(5,11,13,15)}$. The experiments were performed in a split-litter manner that included one of the treatments and controls at two different time points per litter (three to four rat pups $\times 2$ litters/group) (Fig. 1).

\section{Intestinal in vivo permeability test}

At each time point, 1, 4, 8 and $24 \mathrm{~h}$ after gut provocation, intestinal macromolecular permeability was assessed by oral administration of a marker cocktail containing human serum albumin (HSA; Sigma-Aldrich, $1.25 \mathrm{mg} / \mathrm{g}$ b.wt), bovine $\operatorname{IgG}$ (BIgG, $0.25 \mathrm{mg} / \mathrm{g} \mathrm{b}$. wt; Sigma-Aldrich) and fluorescein isothiocyanate-conjugated dextran (FITC-dextran 4kDa, FD4, 0.1425 mg/g b.wt; TdB Consultancy $\mathrm{AB}$ ) followed by the collection of blood $3 \mathrm{~h}$ later. Alternatively, a different marker cocktail containing BIgG (0.25 mg/g b.wt; Sigma-Aldrich) and HSA (1.25 mg/g b.wt; SigmaAldrich) together with FITC-dextran $70 \mathrm{kDA}$ (FD70, $1.25 \mathrm{mg} / \mathrm{g} \mathrm{b}$. wt; TdB Consultancy AB) and the low-molecular-weight sugars, lactulose $(0.5 \mathrm{mg} / \mathrm{g}$ b.wt; Meda $\mathrm{AB})$ and mannitol $(0.3 \mathrm{mg} / \mathrm{g}$ b.wt; Sigma-Aldrich), was used.

\section{Animal euthanasia and organ collection}

At $3 \mathrm{~h}$ after marker cocktail oral administration, the rats were euthanised by inhalation of isoflurane (Abbott). After laparotomy, urine was collected from the bladder. The total urine volume was measured and the urine was then stored at $-70^{\circ} \mathrm{C}$. Thereafter, the thorax was opened and blood was collected by cardiac puncture into EDTA-containing syringes and plasma was obtained by blood centrifugation at $3000 \boldsymbol{g}$ for $15 \mathrm{~min}$ at $+4^{\circ} \mathrm{C}$ and stored at $-20^{\circ} \mathrm{C}$ until further analysis. The spleen and pancreas were then dissected out, weighed and the pancreas was stored at $-70^{\circ} \mathrm{C}$. The SI was dissected from the pylorus to the ileo-caecal junction and the length was measured. The SI was divided into two equal halves, proximal and distal, the luminal content was immediately flushed out with $1 \mathrm{ml}$ of ice-cold $0.2 \mathrm{~m}$ TRIS-HCl buffer $+0.05 \mathrm{M} \mathrm{CaCl}_{2}, \mathrm{pH} 7 \cdot 8$, collected and stored at $-70^{\circ} \mathrm{C}$. The weights of the flushed SI halves

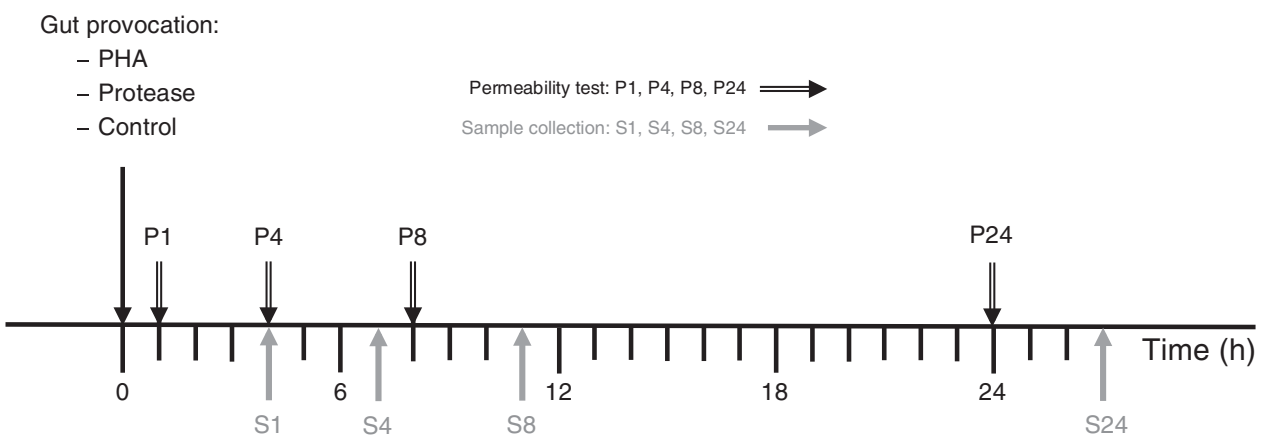

Fig. 1. Experimental design indicating treatment administration, permeability marker oral administration $(\mathrm{P})$ and the following sample collection (S) time points. PHA, phytohaemagglutinin. 
were notated and tissue samples were taken from the middle part of each half, fixed in $10 \%$ neutral-buffered formalin for $24 \mathrm{~h}$ and then kept in $70 \%$ ethanol until paraffin-embedding using standard procedures. The remaining SI tissue was stored at $-70^{\circ} \mathrm{C}$

\section{Intestinal histology}

SI sections, 5- $\mu$ m-thick, were deparaffinised and nuclear staining with bisbenzimide (Hoechst staining of nucleic acid) was performed according to standard procedures. Fluorescence microscopy examination of FD70 uptake was performed using an Olympus microscope (Olympus) connected to a Nikon digital camera (Nikon Imaging Japan Inc.). The images were adjusted and analysed using the Image $1.49 \mathrm{~h}$ software (Wayne Rasband, National Institutes of Health; http://imagej.nih.gov/ij).

\section{Plasma analyses}

The plasma concentration of the permeability marker HSA was measured by electroimmunoassay ${ }^{(16)}$ using rabbit anti-HSA (Dako) as the precipitating antibody and purified HSA as the standard, whereas the BIgG concentration was determined by single radial immunodiffusion ${ }^{(17)}$ using rabbit anti-BIgG as the precipitating antibody (Sigma-Aldrich) and purified BIgG as the standard.

The plasma concentration of the fluorescent markers FD4 and FD70 was measured by spectrophotofluorometry at an excitation of $485 \mathrm{~nm}$ ( $9 \mathrm{~nm}$ band width) and an emission wavelength of $535 \mathrm{~nm}$ ( $15 \mathrm{~nm}$ band width), using serially diluted FITC-dextrans as the standard. Plasma from rats not administered with FITC-dextran was used as background.

\section{Urine analyses}

The urine concentration of lactulose was quantified by a threestep process oxidation of lactulose in the presence of NADP to generate NADPH, which was quantified with a spectrophotometer at a wavelength of $340 \mathrm{~nm}$. Urine mannitol concentration was measured by the conversion of mannitol to fructose and $\mathrm{NADH}$, which was then measured spectrophotometrically at $340 \mathrm{~nm}$. In both the assays the generation of NADPH and NADH was proportional to the initial concentration of lactulose and mannitol, respectively ${ }^{(18)}$. The ratio between urine concentrations of lactulose and mannitol was calculated and used as a measure of intestinal permeability.

\section{Pancreatic and luminal content analyses}

The pancreata were homogenised in ice-cold $0.2 \mathrm{~m}$ TRIS-HCl buffer $+0.05 \mathrm{M} \mathrm{CaCl}_{2}$, pH $7.8(1: 10, \mathrm{w} / \mathrm{vol})$, using a glass homogeniser, and centrifuged at $15000 \mathrm{~g}$ for $20 \mathrm{~min}$ at $+4^{\circ} \mathrm{C}$. The SI luminal content was thawed, thoroughly re-suspended with a vortex and centrifuged at $24000 \boldsymbol{g}$ for $30 \mathrm{~min}$ at $+4^{\circ} \mathrm{C}$. Trypsin activity in the supernatants was determined spectrophotometrically using a microplate modification ${ }^{(19)}$ of the method described by Fritz et al. ${ }^{(20)}$, after activation with enteropeptidase (Sigma-Aldrich) and with benzoyl-DL-arginine4-nitroanilide (Sigma-Aldrich) as the substrate. The trypsin activity in units (U) was recalculated as the amount of enzyme that catalyses $1 \mu \mathrm{mol}$ of substrate per minute. The protein concentration in the supernatants was determined using a modification of the Lowry method for ninetysix-well microplates ${ }^{(21)}$ and using purified bovine serum albumin (Sigma-Aldrich) as the standard.

\section{Calculations and statistics}

All data are presented as means and standard deviations. Organ weights were recalculated relative to body weight ( $\mathrm{mg} / \mathrm{g} \mathrm{b.wt)}$ to minimise individual variation. Pancreatic protein and trypsin activity were expressed relative to pancreatic wet weight. Statistical analysis was performed using Prism v7 for Mac OS X (GraphPad Software; www.graphpad.com). Comparisons between PHA and protease treatment and the corresponding controls were performed using an unpaired $t$ test with a HolmSidak multiple comparisons correction. Statistical analyses within the same treatment or control over time were performed using a two-way ANOVA with a Tukey's post hoc correction. Differences were considered significant when $* P<0.05$, *** $P<0.01$, **** $P<0.001$ and ***** $P<0.0001$.

\section{Results}

\section{General performance and body weight changes}

Body weight changes were measured at 8 and $24 \mathrm{~h}$ after enteral provocation (Table 1). After $8 \mathrm{~h}$, oral administration with both PHA and protease resulted in a decrease in body weight compared with that observed in control littermates that gained weight. After $24 \mathrm{~h}$, significant weight loss was still observed in the PHA-treated rats, whereas those treated with protease displayed a recovery of body mass. In addition, loose stools around the anus as a sign of diarrhoea was observed from $8 \mathrm{~h}$ after treatment; however, already at 1 and $4 \mathrm{~h}$ fluid-filled intestines could be observed at autopsy, especially in proteasetreated rats. After $24 \mathrm{~h}$, both provocative agents caused the pancreas to appear more translucent than in control rats.

\section{Organ weights}

The abdominal organs weights were measured and normalised per gram body weight (mg/g b.wt). The SI weight was not affected until $24 \mathrm{~h}$ after provocation, where significantly increased weights of both SI halves were observed following protease treatment, whereas only a significant increase in proximal SI weights was observed following PHA treatment. Spleen weight was significantly decreased at 4 and $24 \mathrm{~h}$ after PHA treatment, whereas treatment with protease resulted in a significant decrease in spleen weight only at $8 \mathrm{~h}$ after treatment.

\section{Pancreatic weight and content}

Pancreatic weight was not significantly affected by protease or PHA treatment (Table 2). However, the pancreatic protein content, representing mainly digestive enzymes, significantly decreased $24 \mathrm{~h}$ after PHA treatment. Trypsin activity was markedly decreased at $24 \mathrm{~h}$ after both PHA and protease 
Table 1. Early effects on body and organ weights after enteral provocation with phytohaemagglutinin (PHA) and protease in neonatal rats (Mean values and standard deviations)

\begin{tabular}{|c|c|c|c|c|c|c|c|c|}
\hline \multirow[b]{2}{*}{ Treatments $\dagger$} & \multicolumn{2}{|c|}{$1 \mathrm{~h}$} & \multicolumn{2}{|c|}{$4 \mathrm{~h}$} & \multicolumn{2}{|c|}{$8 \mathrm{~h}$} & \multicolumn{2}{|c|}{$24 \mathrm{~h}$} \\
\hline & Mean & SD & Mean & SD & Mean & SD & Mean & SD \\
\hline \multicolumn{9}{|c|}{ Body weight change (q) } \\
\hline Control & \multicolumn{2}{|c|}{ ND } & \multicolumn{2}{|c|}{ ND } & +0.7 & 0.5 & $+2 \cdot 2$ & 0.4 \\
\hline PHA & \multicolumn{2}{|c|}{ ND } & \multicolumn{2}{|c|}{ ND } & $-0.5^{\star *}$ & 0.6 & $-0 \cdot 2^{* \star *}$ & 0.7 \\
\hline Control & \multirow{2}{*}{\multicolumn{2}{|c|}{$\begin{array}{l}\text { ND } \\
\text { ND }\end{array}$}} & \multicolumn{2}{|c|}{ ND } & $+2 \cdot 0$ & 1.8 & $+3 \cdot 0$ & 1.6 \\
\hline Protease & & & & & $-0.7^{\star}$ & 1.3 & +1.5 & 1.5 \\
\hline \multicolumn{9}{|c|}{ SI length (cm/g b.wt) } \\
\hline Control & 1.5 & 0.1 & 1.5 & 0.1 & 1.5 & 0.1 & 1.5 & 0.1 \\
\hline PHA & 1.4 & 0.1 & 1.5 & 0.1 & 1.6 & 0.1 & 1.7 & $0 \cdot 1$ \\
\hline Control & 1.6 & 0.1 & 1.6 & 0.2 & 1.5 & 0.1 & 1.5 & 0.2 \\
\hline Protease & 1.6 & 0.1 & 1.7 & 0.2 & 1.7 & 0.2 & 1.7 & 0.1 \\
\hline \multicolumn{9}{|c|}{ SI proximal (mg/g b.wt) } \\
\hline Control & 14.0 & 1.6 & $13 \cdot 2$ & 1.8 & 13.4 & 0.9 & $13 \cdot 7$ & 1.7 \\
\hline PHA & 11.9 & 1.1 & $12 \cdot 0$ & $1 \cdot 1$ & 12.5 & 1.3 & $18 \cdot 1^{\star *}$ & $2 \cdot 0$ \\
\hline Control & $15 \cdot 6$ & $2 \cdot 2$ & $14 \cdot 2$ & 1.3 & 13.5 & 1.5 & 13.9 & 1.5 \\
\hline Protease & $15 \cdot 7$ & 1.4 & $15 \cdot 3$ & 1.9 & $15 \cdot 0$ & $2 \cdot 1$ & $17 \cdot 9^{\star \star \star \star}$ & 1.1 \\
\hline \multicolumn{9}{|c|}{ SI distal (mg/g b.wt) } \\
\hline Control & 11.4 & 0.8 & 11.3 & 0.5 & $11 \cdot 2$ & 0.9 & $12 \cdot 8$ & $2 \cdot 1$ \\
\hline PHA & $12 \cdot 1$ & 0.8 & 11.2 & 0.6 & 13.0 & 1.3 & 14.7 & $2 \cdot 2$ \\
\hline Control & $12 \cdot 5$ & 1.3 & 11.9 & $2 \cdot 1$ & 11.0 & 1.7 & 11.2 & 0.8 \\
\hline Protease & $15 \cdot 0$ & 1.9 & $12 \cdot 1$ & 1.9 & $11 \cdot 7$ & 0.5 & $13 \cdot 9^{*}$ & 1.5 \\
\hline \multicolumn{9}{|c|}{ Spleen (mg/g b.wt) } \\
\hline Control & 3.6 & 0.5 & 3.7 & 0.2 & $3 \cdot 1$ & 0.4 & $3 \cdot 2$ & 0.4 \\
\hline PHA & 3.2 & 0.2 & $2 \cdot 8^{\star *}$ & $0 . \overline{3}$ & $2 \cdot 6$ & 0.2 & $2 \cdot 5^{\star}$ & 0.5 \\
\hline Control & $3 \cdot 1$ & 0.4 & $2 \cdot 9$ & 0.4 & 3.4 & 0.6 & 3.4 & 0.2 \\
\hline Protease & 2.9 & 0.3 & 2.9 & 0.4 & $3 \cdot 1^{*}$ & 0.3 & $3 \cdot 3$ & 0.4 \\
\hline
\end{tabular}

b.wt, body weight; ND, not determined.

Differences between treatments and the corresponding control group were considered statistically significant: ${ }^{\star} P<0.05,{ }^{\star \star} P<0.01,{ }^{\star \star \star} P<0.001,{ }^{\star \star \star \star} P<0.0001$. $\dagger 14$-d-old suckling rat pups were treated by oral administration with PHA, protease (trypsin) or control (water). Number of individuals per group, $n$ 5-7.

Table 2. Early effects on pancreas weight and pancreatic content of protein and trypsin after enteral provocation with phytohaemagglutinin (PHA) and protease in neonatal rats (Mean values and standard deviations)

\begin{tabular}{|c|c|c|c|c|c|c|c|c|}
\hline \multirow[b]{2}{*}{ Treatments $†$} & \multicolumn{2}{|c|}{$1 \mathrm{~h}$} & \multicolumn{2}{|c|}{$4 \mathrm{~h}$} & \multicolumn{2}{|c|}{$8 \mathrm{~h}$} & \multicolumn{2}{|c|}{$24 \mathrm{~h}$} \\
\hline & Mean & SD & Mean & SD & Mean & SD & Mean & SD \\
\hline \multicolumn{9}{|c|}{ Pancreas weight (mg/g b.wt) } \\
\hline Control & $2 \cdot 6$ & 0.4 & $2 \cdot 9$ & 0.3 & $2 \cdot 4$ & 0.3 & $2 \cdot 2$ & $0 \cdot 1$ \\
\hline PHA & $2 \cdot 6$ & 0.3 & $3 \cdot 1$ & 0.8 & $2 \cdot 3$ & 0.3 & $2 \cdot 4$ & 0.2 \\
\hline Control & $2 \cdot 7$ & 0.4 & 2.9 & 0.5 & $2 \cdot 3$ & 0.4 & $2 \cdot 2$ & 0.4 \\
\hline Protease & $2 \cdot 7$ & 0.4 & $3 \cdot 0$ & 0.3 & $2 \cdot 4$ & 0.4 & $2 \cdot 3$ & 0.4 \\
\hline \multicolumn{9}{|c|}{ Protein ( $\mu \mathrm{g} / \mathrm{mg}$ pancreas) } \\
\hline Control & $48 \cdot 2$ & $4 \cdot 1$ & $45 \cdot 4$ & 5.4 & 64.9 & $7 \cdot 7$ & $70 \cdot 2$ & 5.4 \\
\hline PHA & $49 \cdot 7$ & 4.6 & $47 \cdot 7$ & $5 \cdot 3$ & 65.4 & 10.9 & $47 \cdot 2^{\star \star *}$ & 5.5 \\
\hline Control & $61 \cdot 6$ & $6 \cdot 4$ & $57 \cdot 3$ & 5.4 & 73.5 & 6.5 & $72 \cdot 2$ & 8.6 \\
\hline Protease & $69 \cdot 8$ & $7 \cdot 8$ & $66 \cdot 0$ & 11.6 & 83.8 & $15 \cdot 1$ & $60 \cdot 9$ & 9.6 \\
\hline \multicolumn{9}{|c|}{ Trypsin (U/mg pancreas) } \\
\hline Control & $2 \cdot 7$ & 0.7 & $2 \cdot 9$ & 0.3 & 3.5 & 0.9 & $4 \cdot 3$ & 0.7 \\
\hline PHA & $2 \cdot 4$ & 0.4 & $3 \cdot 2$ & 0.9 & $2 \cdot 6$ & 0.7 & $0 \cdot 2^{\star \star \star}$ & 0.1 \\
\hline Control & $3 \cdot 3$ & 0.6 & 3.0 & 0.5 & $4 \cdot 1$ & 0.6 & 3.7 & 0.9 \\
\hline Protease & $4 \cdot 2$ & 0.7 & $4 \cdot 3$ & $1 \cdot 1$ & 4.9 & 1.4 & $1.5^{\star}$ & $1 \cdot 1$ \\
\hline \multicolumn{9}{|c|}{ Trypsin (U/mg protein) } \\
\hline Control & 52.3 & $17 \cdot 4$ & $63 \cdot 6$ & $8 \cdot 1$ & 54.5 & $12 \cdot 5$ & 61.5 & 11.5 \\
\hline PHA & $47 \cdot 8$ & $5 \cdot 3$ & $67 \cdot 8$ & $19 \cdot 1$ & $39 \cdot 3$ & $10 \cdot 3$ & $5 \cdot 1^{\star \star \star \star}$ & 1.4 \\
\hline Control & 53.0 & $9 \cdot 9$ & $52 \cdot 1$ & 9.8 & $56 \cdot 5$ & 12.5 & $50 \cdot 6$ & 11.8 \\
\hline Protease & 59.9 & 4.4 & 65.9 & $13 \cdot 7$ & $58 \cdot 8$ & $13 \cdot 1$ & $24.0^{*}$ & $16 \cdot 0$ \\
\hline
\end{tabular}

b.wt, body weight; $\mathrm{U}$, units.

Differences between treatments and the corresponding control group were considered statistically significant: ${ }^{*} P<0.05,{ }^{\star \star} P<0.01,{ }^{\star \star \star} P<0.001,{ }^{\star \star \star \star} P<0.0001$.

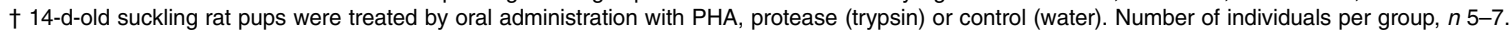

treatments in comparison with their respective controls. Moreover, the calculated trypsin to total protein ratio was significantly decreased at $24 \mathrm{~h}$ after both PHA and protease treatments, with stronger effects caused by the PHA treatment.

\section{Trypsin activity in the luminal content}

Trypsin activity in the luminal content of the proximal SI was up to 500-fold higher in the protease (trypsin)-treated group 
(a)

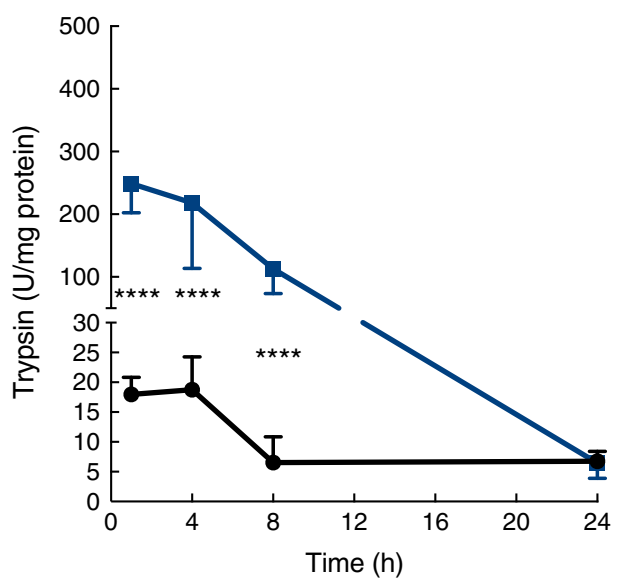

(c)

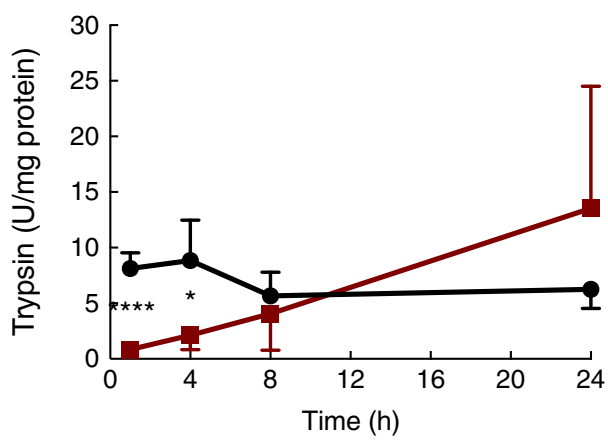

(b)

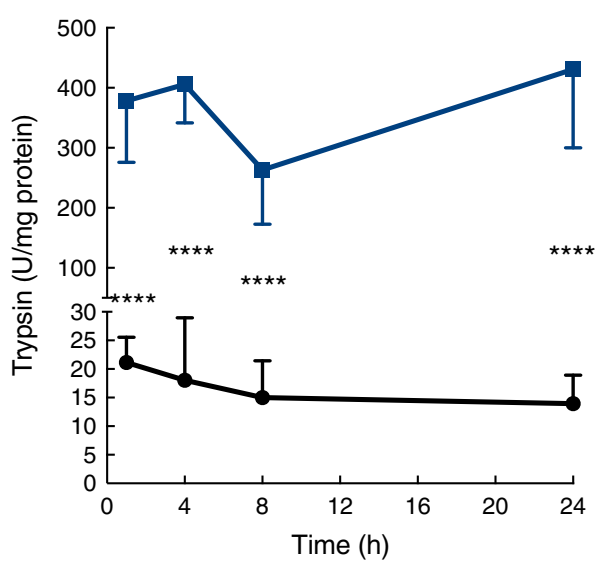

(d)

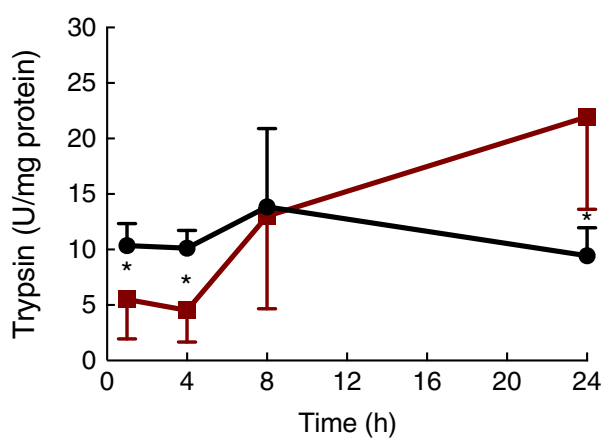

Fig. 2. Intestinal proteolytic activity. Trypsin activity per mg protein (units (U)/mg protein) in the luminal content of the proximal (a, c) and distal (b, d) small intestine (SI) at $1,4,8$ and $24 \mathrm{~h}$ after luminal provocation of 14 -d-old suckling rats with protease (trypsin) or phytohaemagglutinin (PHA) as compared with water-administered controls. Values are means and standard deviations. Number of rat pups per age group is between 5 and 7 . a and b: $\longrightarrow$, Control; $\longrightarrow$ - , protease; c and d: $\longrightarrow-$ control; - , PHA. Differences between the treatment groups and controls were considered to be significant: ${ }^{*} P<0.05,{ }^{\star * \star \star} P<0.0001$.

compared with that in the controls after $1 \mathrm{~h}$, but then gradually decreased until reaching the level of the control group at $24 \mathrm{~h}$ (Fig. 2(a)). Trypsin activity in luminal content of the distal SI was initially about 500-fold higher compared with that observed in the control group and remained elevated for up to $24 \mathrm{~h}$ after oral administration (Fig. 2(b)). In the PHA-treated group, trypsin activity in the luminal content of both the proximal and distal SI was significantly lower than that observed in controls at 1 and $4 \mathrm{~h}$ after oral administration; afterwards, trypsin activity in the distal SI gradually increased until they reached significantly higher levels at $24 \mathrm{~h}$ after both treatments (Fig. 2(c) and (d)).

\section{Intestinal permeability}

The immediate effects of the two provocative agents on intestinal permeability were tested in vivo by feeding a cocktail of macromolecule markers, containing BIgG and HSA, together with the low-molecular-weight marker FD4 (Fig. 3). Plasma levels of BIgG were significantly decreased at all time points in both treatment groups compared with the corresponding water-fed control pups (Fig. 3(a)). Plasma levels of HSA were significantly lower compared with controls at all time points in the PHA-treated group, whereas in the protease group plasma HSA levels were only significantly decreased from $8 \mathrm{~h}$ after treatment (Fig. 3(b)).
In contrast, plasma levels of FD4 were significantly increased at 1 , 4 and $8 \mathrm{~h}$ after protease treatment, whereas at $24 \mathrm{~h}$ it had decreased to levels lower than that observed in controls (Fig. 3(c)). In the PHA-treated group, no major differences in FD4 plasma levels were observed compared with controls, except for significantly lower values observed at 4 and $8 \mathrm{~h}$ after treatment.

The early increase in intestinal passage of FD4 and the apparently unchanged HSA passage until $8 \mathrm{~h}$ after protease treatment prompted us to further investigate intestinal permeability and integrity by using an alternative marker cocktail containing BIgG and HSA together with the tissue-traceable fluorescent macromolecular marker FD70 and the low-molecularweight sugars, lactulose and mannitol, as integrity markers (Fig. 4). Confirming the previous results, plasma levels of BIgG were significantly lower at both 1 and $8 \mathrm{~h}$ in the protease group compared with those in control littermates (Fig. 4(a), upper left panel), whereas the plasma levels of HSA were unaffected at $1 \mathrm{~h}$, but had significantly decreased at $8 \mathrm{~h}$ after treatment (Fig. 4(a), lower left panel). In contrast, the plasma FD70 level was already significantly increased $1 \mathrm{~h}$ after treatment and was still higher compared with controls at $8 \mathrm{~h}$ (Fig. 4(a), lower right panel).

The urine lactulose:mannitol ratio (Lac:Man) was significantly increased at both time points in the protease-treated group (Fig. 4(a), upper right panel) compared with controls. A closer 

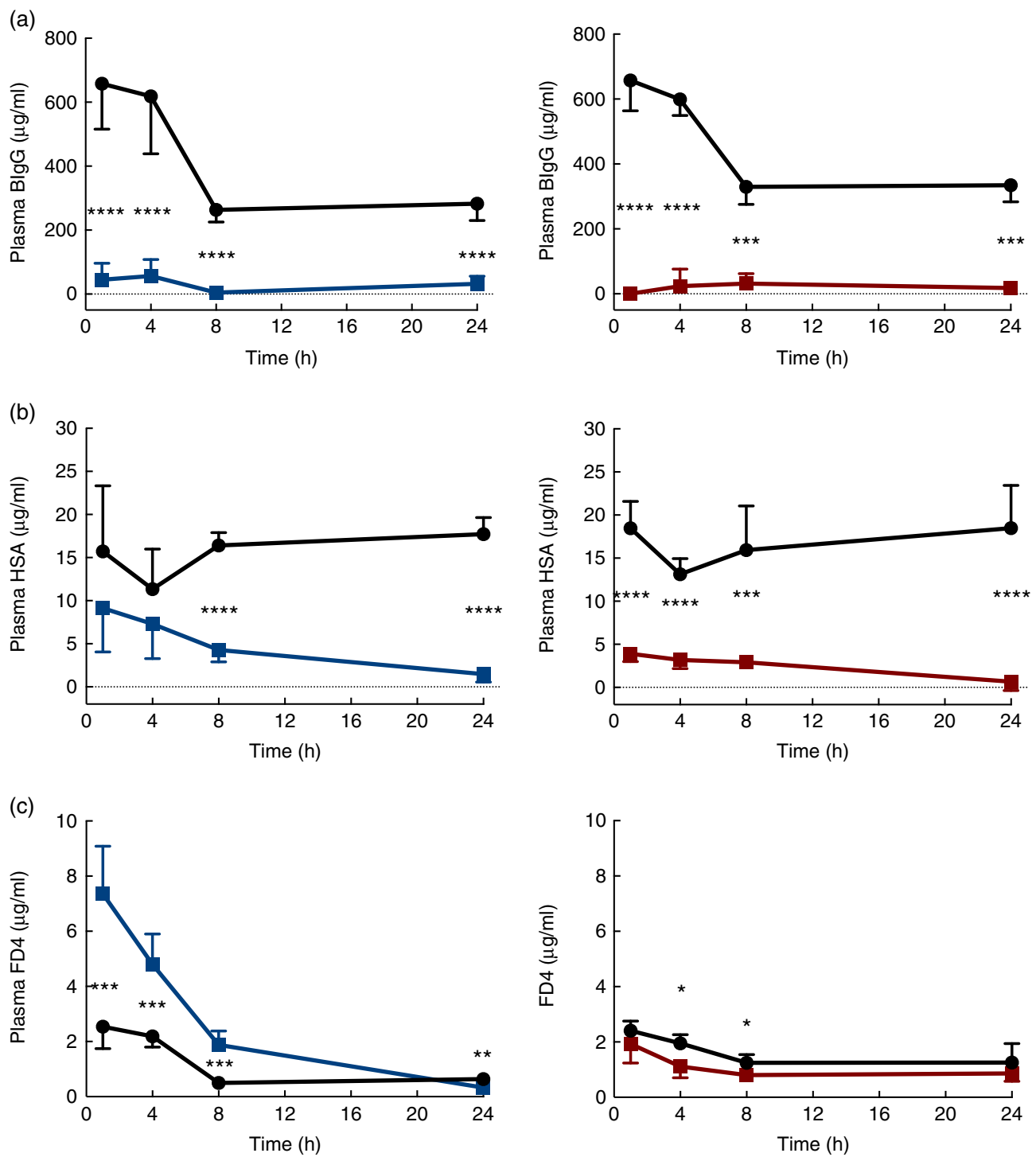

Fig. 3. Intestinal in vivo permeability. Blood plasma levels $3 \mathrm{~h}$ after oral administration of the marker molecules bovine lgG (BlgG, a), human serum albumin (HSA, b) and fluorescein isothiocyanate (FITC)-dextran 4 (FD4, c) at 1, 4, 8 and $24 \mathrm{~h}$ after luminal provocation of 14-d-old rats with protease or phytohaemagglutinin (PHA) as compared with water-administered controls. Values are means and standard deviations. - , Control; - - protease; - , PHA. Differences between the treatment groups and controls were considered significant: ${ }^{\star} P<0.05,{ }^{\star \star} P<0.01,{ }^{\star \star \star} P<0.001,{ }^{\star \star \star \star} P<0.0001$.

analysis of the increased Lac:Man ratio showed that both mannitol and lactulose urine concentrations were increased, but only the total amount of lactulose excreted was significantly increased at 1 and $8 \mathrm{~h}$ after protease treatment (Table 3). Significantly smaller urine volumes were collected from the protease-treated rats compared with controls during the 3-h period.

The uptake of FD70 by intestinal epithelial cells was also analysed by fluorescence microscopy (Fig. 4(b)). In the proximal SI, the control group showed green apical spots (vesicles); however, $1 \mathrm{~h}$ after protease provocation, no vesicles could be observed. In the distal SI, FD70 was seen mainly around the supranuclear vacuoles in the control group, whereas $1 \mathrm{~h}$ after protease treatment FD70 uptake was higher and with a different distribution, observed mainly as intracytoplasmic and intravacuolar vesicles. At $8 \mathrm{~h}$ after protease provocation, the difference in FD70 uptake in the distal SI was less evident between the control and the protease-treated groups (not shown).

\section{Discussion}

\section{General performance and effects on abdominal organs}

The present study investigated the early effects of enteral provocation with protease in comparison with those caused by PHA in the suckling rat model. Both treatments resulted in body weight loss after $8 \mathrm{~h}$, in contrast to the normal weight gain as observed in water-fed controls. The weight loss was observed to coincide with the onset of signs of diarrhoea (i.e. fluid-filled intestines) and loose stools. The fluid loss was also reflected in the decreased urine volumes observed after protease treatment compared with controls. However, $24 \mathrm{~h}$ after treatment, the protease-treated 

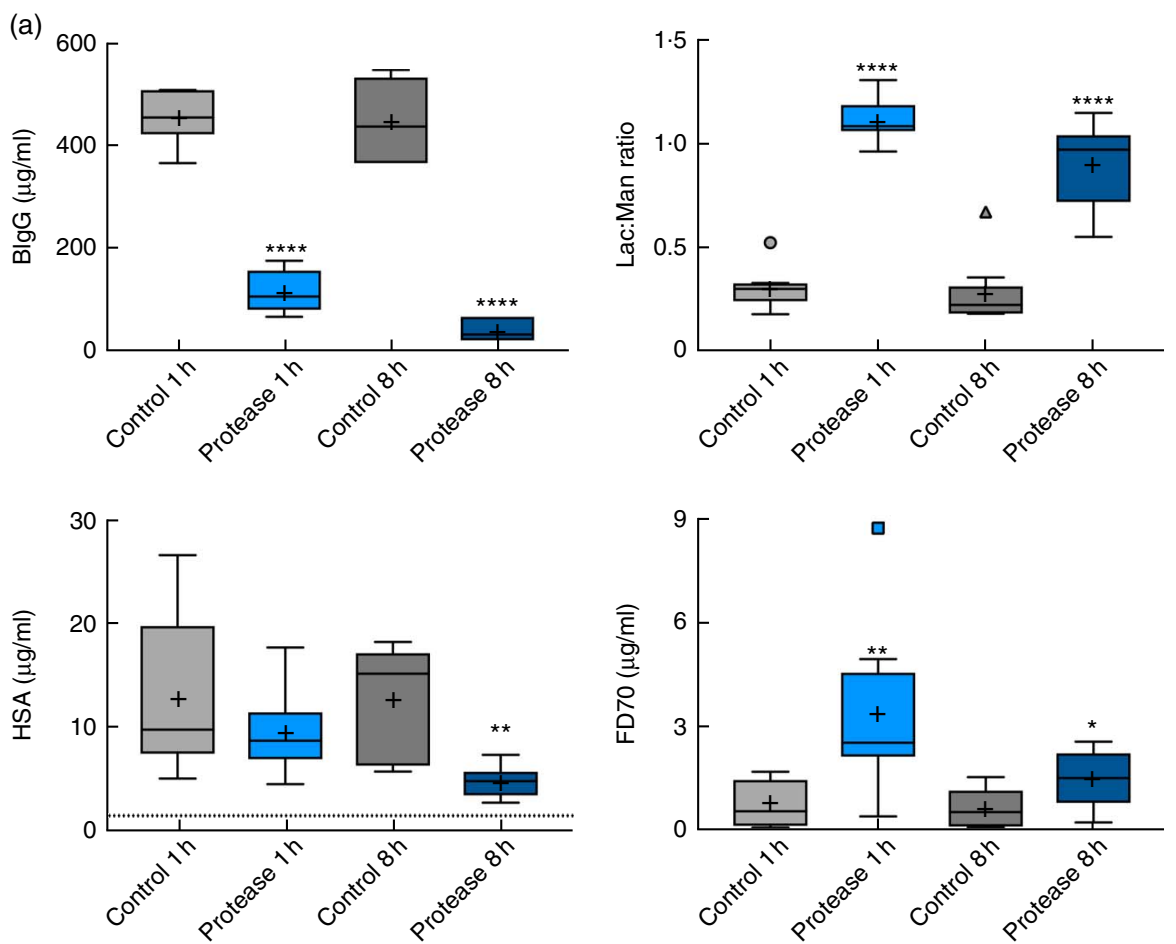

(b)

Control $1 \mathrm{~h}$

Protease $1 \mathrm{~h}$
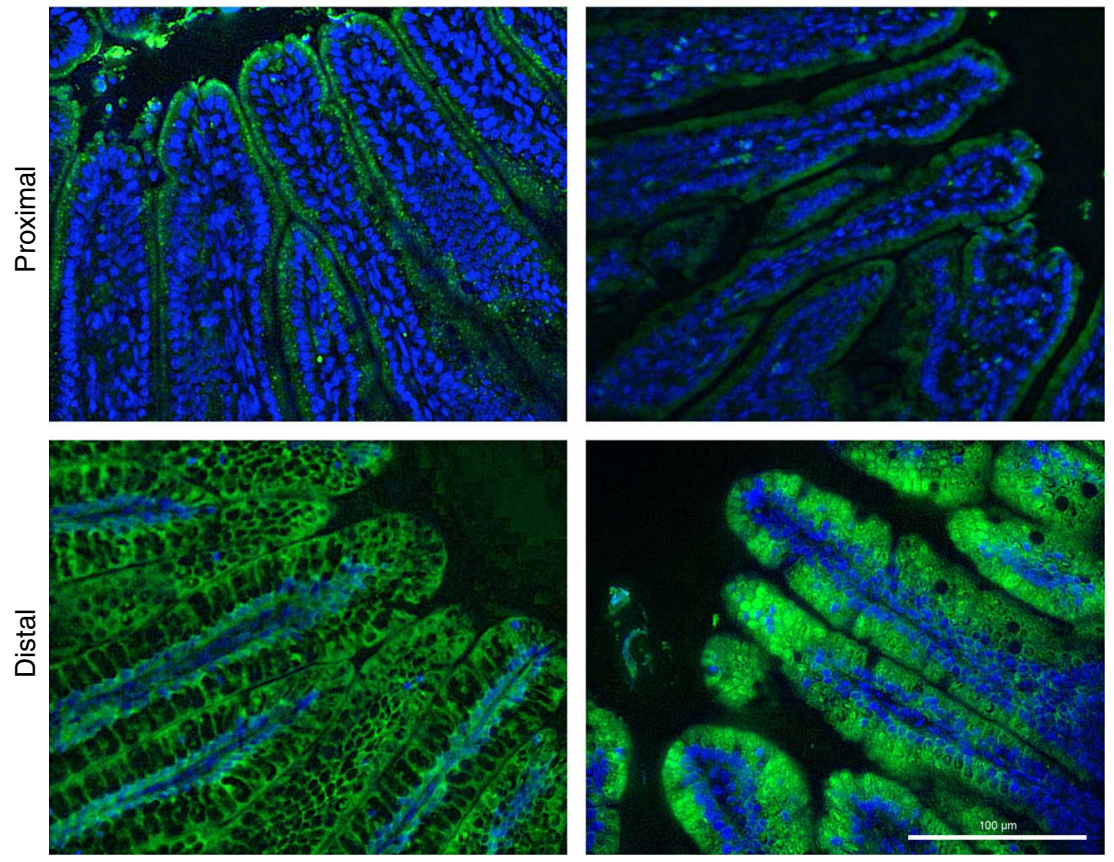

Fig. 4. Intestinal in vivo uptake and permeability. (a) Marker molecule levels $3 \mathrm{~h}$ after oral administration: bovine lgG (BlgG, upper left), human serum albumin (HSA, lower left) and fluorescein isothiocyanate-dextran 70 (FD70, lower right) in blood plasma, and the lactulose:mannitol ratio (Lac:Man, upper right) in urine, in neonatal rats at 1 and $8 \mathrm{~h}$ after luminal provocation with protease (trypsin) as compared with water-administered controls. Values are in boxplot: box line, median; + , mean; \pm bars, inner fences, outliers defined by Tukey's method. Differences between the treatment groups and controls were considered significant: * $P<0.05,{ }^{* \star} P<0.01$, **** $P<0.0001$. (b) FITC-D70 direct detection by fluorescence microscopy in the small intestine of 14-d-old rats after the in vivo permeability test performed $1 \mathrm{~h}$ after enteral provocation with protease or control. Representative images showing sections from the proximal and distal SI (400x) (scale bar 100 $\mu \mathrm{m})$. In green FD70, which is a permeability marker with intrinsic fluorescence $(\lambda 488)$, and nuclei in blue, stained with bisbenzimide.

group had recovered and started to gain body weight, whereas the PHA-treated pups had not yet fully recuperated. This indicated that PHA provocation caused a longer period of diarrhoea and had more severe effects on intestinal assimilation of nutrients, which matched previously known binding effects of the PHA to the intestinal epithelium causing villi dystrophy and malabsorption ${ }^{(22)}$. 
Table 3. Early effects on intestinal integrity by using the marker molecules lactulose and mannitol in urine after enteral provocation with protease and phytohaemagglutinin $(\mathrm{PHA})$ on neonatal rats (Mean values and standard deviations)

\begin{tabular}{|c|c|c|c|c|}
\hline \multirow[b]{2}{*}{ Treatments $\dagger$} & \multicolumn{2}{|c|}{$1 \mathrm{~h}$} & \multicolumn{2}{|c|}{$8 \mathrm{~h}$} \\
\hline & Mean & SD & Mean & SD \\
\hline \multicolumn{5}{|c|}{ Mannitol $(\mathrm{mg} / \mathrm{ml}) \ddagger$} \\
\hline Control & $2 \cdot 17$ & 1.19 & $1 \cdot 76$ & 0.69 \\
\hline Protease & $3.79^{*}$ & 1.60 & $4 \cdot 50^{\star \star \star}$ & 1.76 \\
\hline \multicolumn{5}{|c|}{ Lactulose $(\mathrm{mg} / \mathrm{ml}) \ddagger$} \\
\hline Control & 0.67 & 0.46 & 0.52 & 0.48 \\
\hline Protease & $4 \cdot 27^{\star \star \star \star}$ & 2.09 & $4 \cdot 22^{\star \star \star \star}$ & $2 \cdot 01$ \\
\hline \multicolumn{5}{|c|}{ Total mannitol (mg) } \\
\hline Control & 0.77 & 0.27 & 0.71 & 0.20 \\
\hline Protease & 0.60 & 0.23 & 0.72 & 0.29 \\
\hline \multicolumn{5}{|c|}{ Total lactulose (mg) } \\
\hline Control & 0.24 & 0.15 & 0.21 & 0.17 \\
\hline Protease & $0.66^{\star \star}$ & 0.25 & $0 \cdot 66^{\star \star \star}$ & 0.33 \\
\hline \multicolumn{5}{|c|}{ Urine volume $(\mathrm{ml})$} \\
\hline Control & 0.43 & 0.21 & 0.47 & 0.22 \\
\hline Protease & $0.19^{* *}$ & $0 \cdot 10$ & $0 \cdot 16^{\star * *}$ & 0.06 \\
\hline
\end{tabular}

Differences between each time point after protease treatment compared with the corresponding control group were considered statistically significant: ${ }^{*} P<0.05$, ${ }^{\star \star} P<0.01,{ }^{\star \star \star} P<0.001,{ }^{\star \star \star \star} P<0.0001$.

$\dagger 14$-d-old suckling rat pups were treated by oral administration with protease (trypsin) or control (water). Number of individuals per group, $n 9$.

$\ddagger$ Urine measurement of lactulose and mannitol $3 \mathrm{~h}$ after oral administration.

Enteral exposure to both protease and PHA resulted in increased SI weight after $24 \mathrm{~h}^{(10)}$, indicating stimulated SI growth, as previously shown $24 \mathrm{~h}$ after PHA provocation with increased proliferating $\mathrm{PCNA}^{+}$cells in the intestinal crypts ${ }^{(12)}$. In addition, the stomach and caecum were shown to start increasing in weight $48 \mathrm{~h}$ after PHA treatment ${ }^{(10,12)}$.

Spleen weights decreased by about $20 \%$ after PHA provocation compared with the control group, whereas the effect of protease treatment was less evident. In previous studies the decrease in spleen weight within $12 \mathrm{~h}$ after PHA oral administration was related to the recruitment of $\mathrm{CD} 19^{+} \mathrm{B}$ cells and $\mathrm{CD} 3^{+}$ $\mathrm{T}$ cells to the gut mucosa ${ }^{(13)}$. In the present study, pancreatic weight was not significantly affected by either of the treatments during the $24 \mathrm{~h}$ following treatment, which is in agreement with previous studies that have shown that pancreatic weight increased $48 \mathrm{~h}$ after PHA provocation ${ }^{(12)}$.

\section{Effects on pancreatic function}

A more reliable indicator of the effects provoked by the treatments on the pancreas, other than the organ weight, could be the pancreatic enzyme content ${ }^{(3,23)}$. In fact, the trypsin content had decreased at $24 \mathrm{~h}$ after both treatments, indicating a stimulated pancreatic secretion $^{(24)}$, and thus the effects of enteral provocation on the pancreatic function might also be reflected in the intestinal luminal enzyme content. In the PHA-treated rats, the trypsin activity in the luminal content was initially decreased compared with controls during the first $4 \mathrm{~h}$, after which it increased coinciding with decreased trypsin activity in the pancreas, suggesting a somewhat delayed stimulation of pancreatic secretion by the PHA treatment ${ }^{(25-27)}$. We have previously shown that exposure to PHA stimulates pancreas growth and secretion ${ }^{(12)}$; this may be partially through a cholecystokinin (CCK)-dependent mechanism as shown in adult rats ${ }^{(27)}$. However, CCK receptors were less expressed in the pancreas of suckling rats compared with weaned rats ${ }^{(28)}$, which might explain the delay observed in the pancreatic response.

As trypsin was administered to the protease-treated rat pups, the trypsin activity measured in the intestinal lumen was a result of the mixture of the trypsin that was administered and that which was endogenously secreted. Thus, after the initially very high trypsin activity, a gradual decrease in activity was observed in the proximal SI lumen, to levels similar to those observed in controls after $24 \mathrm{~h}$. In the distal SI, trypsin appeared to accumulate and the activity remained high.

\section{Effects on intestinal permeability}

The effects of enteral provocation on the intestinal in vivo permeability was assessed by feeding a marker cocktail containing different-sized marker molecules to the pups and measuring the blood plasma or urine marker levels $3 \mathrm{~h}$ later. The macromolecular markers BIgG, HSA and FD70 were used to assess the effects on macromolecular absorption - that is, the endocytic capacity of the immature intestinal epithelium in neonatal rats ${ }^{(4,29)}$, whereas FD4 and the low-molecular-weight sugar markers, lactulose and mannitol, were used to study the effects on the intestinal mucosal integrity and possible paracellular leakage.

Both PHA and protease treatments promptly and markedly decreased plasma BIgG levels, almost completely hindering the high BIgG absorption observed in control rats. As the uptake of $\mathrm{IgG}$ is mediated by fetal-type enterocytes expressing IgG-binding FCRn receptors in the proximal $\mathrm{SI}^{(5,30)}$, the results indicate that the selective receptor-mediated endocytosis pathway was severely affected by the enteral provocation with both protease and PHA. The reduced BIgG absorption was not re-established within $24 \mathrm{~h}$ after either of the treatments. The fetaltype epithelium is finally replaced by FcRn-negative adult-type enterocytes by gut provocation ${ }^{(11,12)}$; however, this process of complete epithelial renewal takes between 3 and $5 \mathrm{~d}^{(31,32)}$.

In the control groups of rats, the BIgG absorptive capacity appeared to be decreased at 8 and $24 \mathrm{~h}$ compared with that observed at 1 and $4 \mathrm{~h}$. This difference might be a reflection of litter differences, such as maternal production of milk or the milk content of IgG owing to parity of the dam or seasonal fluctuations, as the study was performed in a litter-split mode with controls and treatment groups of rats at two different time points within the same litter. Supporting this interpretation are the similar BIgG permeability results obtained from the control groups within the set of rat pups with data collected from littermates at 1 and $8 \mathrm{~h}$ after oral administration (Fig. 4).

The unspecific absorption of macromolecules mainly takes place in the distal SI by the fetal-type enterocytes with high endocytic capacity and the formation of large supranuclear digestive vacuoles ${ }^{(33,34)}$. The absorption of HSA, used as a marker for non-selective absorption, was prominently decreased already within $1 \mathrm{~h}$ after PHA treatment, whereas in the protease-treated group the decrease was progressive, with HSA absorption becoming significantly lower at $8 \mathrm{~h}$ after treatment and absorption had almost ceased $24 \mathrm{~h}$ after provocation. This suggests that the two treatments have different effects with 
regard to the unspecific macromolecular endocytosis. PHA is a lectin that binds to specific carbohydrates in the brush-border of the intestinal epithelium, apparently blocking the absorptive capacities of the intestinal epithelium ${ }^{(12,35,36)}$. Less is known about the possible effects of protease exposure, but it is thought to provoke a signal for decreasing the endocytosis capability of the epithelial cells, possibly via the protease-activated receptor2 (PAR-2), which is highly expressed in immature SI epithelium during the suckling period ${ }^{(37)}$. Also the possibility that protease oral administration might increase the luminal degradation of the protein markers should be considered; however, the progressive and increasing effects on HSA absorption, along with the decrease in luminal trypsin activity over time, suggest otherwise.

The fluorescencent marker, FITC-dextran 70, which has a similar molecular weight to HSA but is resistant to proteolytic degradation, was used to further evaluate the macromolecular absorption and epithelial uptake. A significant increase in plasma levels of FD70 was observed already within $1 \mathrm{~h}$ of protease oral administration differing from plasma HSA absorption, which remained unchanged. This indicated that even though FD70 has a comparable molecular weight to HSA, FD70 was absorbed in a different manner. In fact, the pattern of absorption of FD70 was instead more alike to that of the markers used to assess paracellular passage - that is, FD4 and Lac:Man. The fluorescence microscopy study provided additional information, indicating a rapid decrease in the epithelial vesicular uptake of FD70 in the proximal SI after protease treatment. At the same time, in the distal SI, the epithelial uptake of FD70 was evidently increased, relating well to the increased plasma level of FD70. The epithelial passage of FD70 in the distal SI seems to occur mostly transcellulary; however, the paracellular epithelial route cannot be excluded and further studies are needed.

Together with lactulose and mannitol, FD4 was used to assess the paracellular permeability and epithelial integrity ${ }^{(38)}$. In the PHA group, only minor effects were observed with even lower levels of FD 4 at 4 and $8 \mathrm{~h}$ after treatment compared with that of the control groups. In contrast, protease treatment resulted in increased passage of FD4 to the blood directly after provocation, which then gradually decreased until nearly disappearing after $24 \mathrm{~h}$. These results indicate that protease treatment caused an instant but temporary increase in the paracellular leakiness of the intestinal barrier that seemed to be overcome within $24 \mathrm{~h}$. The low-molecular-weight sugar markers, lactulose and mannitol, excreted into the urine are considered to be tracers of the paracellular route and indicators of intestinal integrity. In the current study, following protease treatment, increased urinary excretion of both sugar markers and an increased Lac:Man ratio were observed, which indicates a disturbance of the intestine by the protease exposure, causing a temporary increase in paracellular permeability and thus leakiness of the intestinal barrier.

\section{General discussion}

The present study investigated the immediate effects of enteral exposure to protease or PHA, agents capable of inducing precocious gut maturation, on the intestinal mucosa in order to better understand the mechanisms responsible for the early initiation of gut maturation. Interestingly, the results indicate that the mechanisms of initiation are different for the two different provocative agents. Exposure to the lectin PHA blocked the intestinal passage of all permeability marker molecules, whereas protease exposure resulted in a marked decreased macromolecule passage (BIgG and HSA) but also a temporary increase in intestinal leakiness to smaller molecules (FD4 and Lac:Man ratio).

The binding of PHA to specific carbohydrate structures in the brush-border of the intestinal epithelium in the neonatal rat ${ }^{(12)}$ evidently blocked the absorptive endocytosis capability of the intestinal epithelium, both the receptor-mediated (BIgG) and the more unspecific (HSA). Previous studies showed that PHA effects on the intestinal epithelium involved a release of the pro-inflammatory cytokines IL- 6 and IL- $1 \beta$ already $4 \mathrm{~h}$ after administration, including increased plasma haptoglobin $72 \mathrm{~h}$ after the PHA treatment ${ }^{(12,39)}$. However, the inflammatory indicators found in PHA-treated rats do not correlate with changes in permeability ${ }^{(39)}$. The release of cytokines after protease provocation in the neonatal rat has not yet been investigated.

Proteases are naturally present in the intestinal lumen, being of microbial origin or endogenous, such as exocrine pancreatic digestive enzymes. The intestinal effects observed in this study following protease treatment could possibly be explained by the activation of mucosal PAR-2 receptors. The activation of PAR-2 has been shown to occur by pancreatic trypsin or other proteases such as mast cell tryptase ${ }^{(40)}$ and, moreover, has been related to increased paracellular permeability of low-molecularweight integrity markers owing to effects on tight-junction proteins $^{(41-43)}$, which was also observed early after provocation with protease as increased leakiness. Additionally, PAR-2 activation has been described to affect cell proliferation and differentiation $^{(44)}$, and this could relate to the obtained increase in gut length and weight caused by the treatments together with the previously shown later effects inducing precocious gut maturation $^{(11,45)}$. Hence, it would be plausible to suggest the involvement of PAR-2 activation in the initiation of gut maturation at weaning in the young, which is associated with vast changes in the SI mucosa that lead to the concept of 'physiological inflammation, (46).

The findings obtained by the use of the neonatal (suckling) rat as the experimental model might have some potential clinical implications. We have earlier used repeated treatments with a lower dose (PHA or protease) to induce precocious gut maturation to simulate the processes occurring at natural weaning - that is, the gradual transition from the milk-based to a solid-feed diet. However, the model used here with administration of a single high dose would be more similar to abrupt weaning, such as early separation of the offspring from their dam, with a fast compensatory mechanism of accelerated gut maturation. Nonetheless, we use both provocative agents and models for comparison to provide knowledge that helps characterise and comprehend the processes occurring during gut maturation to improve the strategies for preventing and treating the complications that surge owing to gut immaturity in pre-term newborns or in husbandry animals that are weaned early. 


\section{Acknowledgements}

The authors thank Camilla Björklöv and Agnieszka Czopek for animal care and assistance during data collection; Olexandr Fedkiv, $\mathrm{PhD}$, for purifying phytohaemagglutinin from red kidney beans, at the Department of Biology, Lund University; and Elin Skytte for the analysis of lactulose and mannitol at the Department of Veterinary Clinical and Animal Sciences, University of Copenhagen, Denmark.

This work was funded by research grants from the Royal Physiographic Society in Lund, Sweden.

Conception and design of the work: E. A. S. and B. W. Data collection and analysis: E. A. S. and B. W. Data interpretation: E. A. S., O. P. and B. W. Writing the original draft: E. A. S. Critical revision of the article: $\mathrm{O} . \mathrm{P}$. and $\mathrm{B}$. W.

The authors declare that there are no conflicts of interest.

\section{References}

1. Cummins AG, Steele TW, Labrooy JT, et al. (1988) Maturation of the rat small-intestine at weaning - changes in epithelialcell kinetics, bacterial-flora, and mucosal immune activity. Gut 29, 1672-1679.

2. Walthall K, Cappon GD, Hurtt ME, et al. (2005) Postnatal development of the gastrointestinal system: a species comparison. Birth Def Res 74, 132-156.

3. Rakhimov KR, Karimov OR, Kurbanov AS, et al. (2002) Rearrangement of spectrum of digestive proteases in postnatal ontogenesis of rats. J Evol Biochem Physiol 38, 184-188.

4. Pacha J (2000) Development of intestinal transport function in mammals. Physiol Rev 80, 1633-1667.

5. Arevalo Sureda E, Westrom B, Pierzynowski SG, et al. (2016) Maturation of the intestinal epithelial barrier in neonatal rats coincides with decreased FcRn expression, replacement of vacuolated enterocytes and changed blimp-1 expression. PLOS ONE 11, e0164775.

6. Menard S, Cerf-Bensussan N \& Heyman M (2010) Multiple facets of intestinal permeability and epithelial handling of dietary antigens. Mucosal Immunol 3, 247-259.

7. Lee PC \& Lebenthal E (1983) Early weanling and precocious development of small intestine in rats: genetic, dietary or hormonal control. Pediatr Res 17, 645-650.

8. Martin MG, Wu SV \& Walsh JH (1993) Hormonal control of intestinal $\mathrm{Fc}$ receptor gene expression and immunoglobulin transport in suckling rats. J Clin Invest 91, 2844-2849.

9. Dufour C, Dandrifosse G, Forget P, et al. (1988) Spermine and spermidine induce intestinal maturation in the rat. Gastroenterology 95, 112-116.

10. Linderoth A, Biernat M, Prykhodko O, et al. (2005) Induced growth and maturation of the gastrointestinal tract after Phaseolus vulgaris lectin exposure in suckling rats. J Pediatr Gastroenterol Nutr 41, 195-203.

11. Prykhodko O, Pierzynowski SG, Nikpey E, et al. (2015) Pancreatic and pancreatic-like microbial proteases accelerate gut maturation in neonatal rats. PLOS ONE 10, e0116947.

12. Linderoth A, Prykhod'ko O, Ahren B, et al. (2006) Binding and the effect of the red kidney bean lectin, phytohaemagglutinin, in the gastrointestinal tract of suckling rats. Br J Nutr 95, 105-115.

13. Prykhod'ko O, Fed'kiv O, Linderoth A, et al. (2009) Precocious gut maturation and immune cell expansion by single dose feeding the lectin phytohaemagglutinin to suckling rats. Br J Nutr 101, 735-742.

14. Pusztai A \& Watt WB (1974) Isolectins of Phaseolus vulgaris. A comprehensive study of fractionation. Biochim Biophys Acta 365, 57-71.
15. Sureda EA, Gidlund C, Weström B, et al. (2017) Induction of precocious intestinal maturation in T-cell deficient athymic neonatal rats. World J Gastroentero 23, 7531-7540.

16. Laurell CB (1972) Electroimmuno assay. Scand J Clin Lab Inv 124, 21-37.

17. Mancini G, Carbonara AO \& Heremans JF (1965) Immunochemical quantitation of antigens by single radial immunodiffusion. Immunochemistry 2, 235-254.

18. Thymann T, Burrin DG, Tappenden KA, et al. (2006) Formulafeeding reduces lactose digestive capacity in neonatal pigs. Br J Nutr 95, 1075-1081.

19. Pierzynowski SG, Westrom BR, Svendsen J, et al. (1990) Development of exocrine pancreas function in chronically cannulated pigs during 1-13 weeks of postnatal life. J Pediatr Gastroenterol Nutr 10, 206-212.

20. Fritz H, Hartwich G \& Werle E (1966) [On protease inhibitors. I. Isolation and characterization of trypsin inhibitors from dog pancreas tissue and pancreas scretion]. Hoppe Seylers $Z$ Physiol Chem 345, 150-167.

21. Lowry $\mathrm{OH}$, Rosebrough NJ, Farr AL, et al. (1951) Protein measurement with the Folin phenol reagent. J Biol Chem $\mathbf{1 9 3}$, 265-275.

22. Pusztai A, Ewen SW, Grant G, et al. (1990) Relationship between survival and binding of plant lectins during small intestinal passage and their effectiveness as growth factors. Digestion 46, Suppl. 2, 308-316.

23. Zoppi G, Andreotti G, Pajno-Ferrara F, et al. (1972) Exocrine pancreas function in premature and full term neonates. Pediatr Res 6, 880-886.

24. Kisfalvi K, Hajnal F, Varga G, et al. (1993) Influence of gastrointestinal (GI) hormones on suckling, gastric emptying and pancreatic trypsin content in the developing rat. J Dev Physiol 19, 149-155.

25. Herzig KH, Bardocz S, Grant G, et al. (1997) Red kidney bean lectin is a potent cholecystokinin releasing stimulus in the rat inducing pancreatic growth. Gut 41, 333-338.

26. Grant G, Edwards JE, Ewan EC, et al. (1999) Secretion of pancreatic digestive enzymes induced in rats by first-time oral exposure to kidney bean E2L2 lectin is mediated only in part by cholecystokinin (CCK). Pancreas 19, 382-389.

27. Kordas K, Burghardt B, Kisfalvi K, et al. (2000) Diverse effects of phytohaemagglutinin on gastrointestinal secretions in rats. J Physiol Paris 94, 31-36.

28. Washington MC, Murry CR, Raboin SJ, et al. (2011) Cholecystokinin-8 activates myenteric neurons in 21and 35-day old but not 4- and 14-day old rats. Peptides 32, 272-280.

29. Telemo E, Westrom BR \& Karlsson BW (1982) Proteolytic activity as a regulator of the transmission of orally fed proteins from the gut to the blood serum in the suckling rat. Biol Neonate 41, 85-93.

30. Martin MG, Wu SV \& Walsh JH (1997) Ontogenetic development and distribution of antibody transport and Fc receptor mRNA expression in rat intestine. Dig Dis Sci 42, 1062-1069.

31. Kelly D, Begbie R \& King TP (1992) Postnatal intestinal development. In Occasional Publication no. 15, pp. 63-79 [MA Varley, PEV Williams and TL Lawrence, editors]. Edinburgh: British Society of Animal Production.

32. Brittan M \& Wright NA (2004) Stem cell in gastrointestinal structure and neoplastic development. Gut 53, 899-910.

33. Baba R, Fujita M, Tein CE, et al. (2002) Endocytosis by absorptive cells in the middle segment of the suckling rat small intestine. Anat Sci Int 77, 117-123.

34. Kumagai N, Baba R, Sakuma Y, et al. (2011) Origin of the apical transcytic membrane system in jejunal absorptive cells of neonates. Med Mol Morphol 44, 71-78. 
35. Cummings RD \& Kornfeld S (1982) Characterization of the structural determinants required for the high affinity interaction of asparagine-linked oligosaccharides with immobilized Phaseolus vulgaris leukoagglutinating and erythroagglutinating lectins. J Biol Chem 257, 11230-11234.

36. Green ED \& Baenziger JU (1987) Oligosaccharide specificities of Phaseolus vulgaris leukoagglutinating and erythroagglutinating phytohemagglutinins. Interactions with $\mathrm{N}$-glycanase-released oligosaccharides. J Biol Chem 262, 12018-12029.

37. Arévalo Sureda E, Westrom B, Pierzynowski S, et al. (2015) Increased pancreatic protease activity in relation to PAR-2 receptor expression during intestinal postnatal development in rats. 48th Annual meeting of the European Society for Pediatric Gastroenterology, Hepatology and Nutrition (ESPGHAN). Amsterdam, The Netherlands.

38. Volynets V, Reichold A, Bardos G, et al. (2016) Assessment of the Intestinal Barrier with Five Different Permeability Tests in Healthy C57BL/6J and BALB/cJ Mice. Dig Dis Sci 61, 737-746.

39. Prykhod'ko O, Pierzynowski SG \& Westrom BR (2010) Immune suppression by cyclosporin A inhibits phytohemagglutinin-induced precocious gut maturation in suckling rats. J Pediatr Gastroenterol Nutr 50, 473-480.
40. Jacob C, Yang PC, Darmoul D, et al. (2005) Mast cell tryptase controls paracellular permeability of the intestine. Role of protease-activated receptor 2 and beta-arrestins. $J$ Biol Chem 280, 31936-31948.

41. Groschwitz KR, Wu D, Osterfeld H, et al. (2013) Chymasemediated intestinal epithelial permeability is regulated by a protease-activating receptor/matrix metalloproteinase-2dependent mechanism. Am J Physiol-Gastr L 304, G479-G489.

42. Vanuytsel T, Vermeire S \& Cleynen I (2013) The role of Haptoglobin and its related protein, Zonulin, in inflammatory bowel disease. Tissue Barriers 1, e27321.

43. Fasano A (2011) Zonulin and its regulation of intestinal barrier function: the biological door to inflammation, autoimmunity, and cancer. Physiol Rev 91, 151-175.

44. Vergnolle N (2016) Protease inhibition as new therapeutic strategy for GI diseases. Gut 65, 1215-1224.

45. Linderoth A, Prykhod'ko O, Pierzynowski SG, et al. (2006) Enterally but not parenterally administered Phaseolus vulgaris lectin induces growth and precocious maturation of the gut in suckling rats. Biol Neonate 89, 60-68.

46. Fiocchi C (2008) What is 'physiological' intestinal inflammation and how does it differ from 'pathological' inflammation? Inflamm Bowel Dis 14, Suppl. 2, S77-S78. 